\title{
Does Driver Suicide Occur in Iran?
}

\author{
Saxby Pridmore, ${ }^{1,}$ Svetlin Varbanov, ${ }^{2}$ Ian Sale, ${ }^{3}$ and Jamshid Ahmadi ${ }^{4}$ \\ ${ }^{1}$ University of Tasmania, Tasmania, Australia \\ ${ }^{2}$ Department of Psychiatry, Medical University of Varna, Varna, Bulgaria \\ ${ }^{3}$ Private Practice, Hobart, Tasmania, Australia \\ ${ }^{4}$ Substance Abuse Research Centre, Shiraz University of Medical Sciences, Shiraz, IR Iran \\ "Corresponding author: Saxby Pridmore, University of Tasmania, Tasmania, Australia. Tel: +61-409825029, E-mail: s.pridmore@utas.edu.au
}

Received 2015 December 01; Accepted 2016 September 23.

\section{Abstract}

Background: Iran has a relatively low suicide rate and the highest road death rate in the world Objectives: To explore the possibility that driver suicide occurs in Iran.

Methods: Examination of the relevant suicide and road traffic literature.

Results: Suicide in Iran includes self-immolation, hanging and other violent methods. It is stigmatized and suicidal intent and actions may be denied. The choice of suicide method depends on availability and culture. Driver suicide is reported in many countries and represents a small percentage of the total number of suicides. It is a method which may hide the fact of suicide and suggest accident. We could find no report of driver suicide from Iran.

Conclusions: There is great interest in reducing the road toll in Iran. Driver suicide may be occurring but not being reported. If driver suicide has a role in the road deaths of Iran, identification and quantification would be helpful.

Keywords: Suicide, Suicide Prevention, Driver Suicide

\section{Suicide in Iran}

Suicide is a global problem, and the global rate is estimated to be 11.6 per 100000 population per year (1). Iran is a large country with many regions with geographic, socioeconomic and religious differences, leading to regional differences in suicidal behavior (2). Estimates of the suicide rates for the whole country range from 6.7 (3) to 29.6 (4). Importantly, Iran lacks a uniform data collection system, and strong stigma associated with suicide encourages individuals and families to conceal relevant information (5).

The triggers of suicide may include mental disorder (6). Other trigger factors include biological, cultural, sociological and socioeconomic factors (5). A recent ecological study confirmed that men of lower socioeconomic status provinces have higher suicide rates (2).

In Iran, the suicide methods most commonly employed are poisoning with herbicides (7), insecticides, amitriptyline, morphine and ethanol (8), among others, followed by hanging and self-immolation (9).

\section{Self-Immolation in Iran}

Self-immolation, unknown in many countries of the world, is a prominent method of suicide in Iran, India,
Lithuania, Egypt, Bulgaria and Russia, and some other regions. In Mazandaran (Iran) it accounts for $25 \%-40 \%$ of total suicides (10). It is the second most common form of suicide in Iran (11).

In Iran, the overall male to female suicide ratio is 2.3 (2); a higher male count is almost universal around the world. However, in all available reports, in Iran and most other countries, self-immolation is predominantly performed by women: $83 \%$ in Mazandaran (10), and up to $99 \%$ in Tabriz city (11).

The triggers for suicide by self-immolation include triggers for other forms of suicide, including mental disorder and family, marital, economic and educational problems. As the majority of self-immolators are female, attention has been drawn to particular problems for Iranian females, including reduced opportunities, lower levels of education and little if any choice in marriage (12).

In addition, self-immolation has dramatic, religious and ritualistic aspects, and is reported in Hindu, Russian Orthodox and Muslim religions. It has a long history in Islam, being described in the eleventh century as a religious practice of a sect of the Assassins (11). 


\section{The Choice of Suicide Method}

Choice of suicide method depends on the availability of different methods and culture (13). Culture refers to the norms and values of a group of people, and includes customs which are the traditional and accepted ways of responding to people and situations. Singapore, a city-state, is full of skyscrapers and not surprisingly, suicide by jumping from a high place is the most common form of suicide. In countries with high gun ownership, death by gunshot is common. In the past, when the warrior class in Japan was armed by swords, suicide in that group was commonly by disembowelment. In countries where liquid fuel is readily available, suicide by self-immolation is an option.

Charcoal burning suicide is emerging as a suicide method in China, and helium gas suicide is emerging as a suicide method in England and Wales. These methods have recently become available (been discovered) and are becoming accepted means (potential cultural responses) as they are less distressing to the individual and those who must deal with the consequences.

\section{Driver Suicide}

Driver suicides have been widely reported. There are two forms, 1) when the vehicle leaves the road and rolls, collides with a fixed object, falls or similar, and 2) when there is a collision (usually head-on) with another vehicle.

Driver suicide accounts for from $1.1 \%$ to $7.4 \%$ of traffic fatalities (14). The largest study of 1419 fatalities (Finland) found suicide in $5.9 \%$ of traffic fatalities (15). A study in Queensland, a state of Australia, found that from 1990 (when the population was 2.9 million) to 2007 (when the population was 3.3 million) there were 52 confirmed cases and 29 possible cases of driver suicide (16). However, the determination of intention and other difficulties have almost certainly resulted in under-reporting.

Suicide drivers compared to those who complete suicide by other methods, are more likely to be male, between 25 and 44 years of age, to have taken alcohol prior to the crash and to have experienced adverse life events, including relationship conflict, legal and financial problems (16). An estimated $24 \%$ had made previous suicide attempts (17). We could find no account of driver suicide from Iran.

\section{Traffic Deaths in Iran}

Road traffic deaths in Iran account for $9.52 \%$ of total death; there are 43.5 deaths per 100000 population per year, making Iranian roads the most dangerous in the world. Drivers are $91.8 \%$ male (18).
UNICEF (19) states the rate of road accidents in Iran is twenty time the world's average, and that prevention will require attention to speeding, seat-belts, child restraints, helmets, road design, infrastructure and emergency services. In addition, a leading commentator (20) has observed a lack of attention to road safety arising from the fatalism imbedded in the Iranian culture, and that changing this culture would be difficult.

\section{Possible Driver Suicide in Iran}

The Iranian suicide rate appears to be relatively low, but the actual rate may be considerably higher, as the data collection system is not well integrated and there is sometimes (as elsewhere) a desire to deny suicidal acts. Violent suicide methods (self-immolation, hanging, and cutting) have been widely reported. It is unclear, however, whether driver suicide occurs in Iran.

Motor vehicles are readily available in most populated regions.

The use of this method is difficult to identify and quantify, because of the difficulty of proving intention. It is probable that this method is chosen by some individuals so as to deny suicide, thereby leaving the social status of the family undamaged and insurance pay-outs unchallenged.

Driver suicide is known in many countries, and drivers are often males, aged 25 - 40 years, and experiencing a range of predicaments. This age range is consistent with suicide by other means and general road traffic deaths in Iran.

In Australia the overall road death rate is half the suicide rate, and in Bulgaria these rates are equal, while in Iran the road death rate is at least eight (8) times higher than the suicide rate. In these Iranian figures lies the possibility that some driver suicide passes as ordinary fatal road accidents.

Iran has the highest road fatality figures in the world. Most drivers are male and suicide is stigmatized. As far as we are aware there are no Iranian reports of driver suicide. There is WHO, UNICEF and local interest in reducing the road toll in Iran, discovering the role, if any, of suicide would be helpful.

\section{Footnotes}

Authors' Contribution: All authors were involved in the conception of this paper. All contributed information and if not writing the first draft, commented, corrected and added to the first draft. All have read and are happy with the final draft. 
Clinical Trial Registration Code: None declared.

Declaration of Interest: None declared.

\section{References}

1. Varnik P. Suicide in the world. Int J Environ Res Public Health. 2012;9(3):750-71. doi: 10.3390/ijerph9030760.

2. Kiadaliri AA, Saadat S, Shahnavazi H, Haghparast-Bidgoli H. Overall, gender and social inequalities in suicide mortality in Iran, 2006-2010: a time trend province-level study. BMJ Open. 2014;4(8):005227. doi: 10.1136/bmjopen-2014-005227. [PubMed: 25138804].

3. Shirazi HR, Hosseini M, Zoladl M, Malekzadeh M, Momeninejad M, Noorian K, et al. Suicide in the Islamic Republic of Iran: an integrated analysis from 1981 to 2007. East Mediterr Health J. 2012;18(6):607-13. [PubMed: 22888617].

4. Janghorbani M, Sharifirad G. Completed and attempted suicide in Ilam, Iran (1995-2002): incidence and associated factors. Arch Iran Med. 2005;8(2):119-26.

5. Amiri M, Livani A, Moosazadeh M, Mirzajani M, Dehghan A. Seasonal pattern in suicide in Iran. Iran J Psychiatry Behav Sci. 2015;9(3):842.

6. Malakouti S, Nojomi M, Poshtmashadi M. Integrating a suicide prevention program into the primary health care network: a field trial study in Iran. Biomed Res Int. 2015.

7. Delirrad M, Majidi M, Boushehri B. Clinical features and prognosis of paraquat poisoning: a review of 41 cases. Int J Clin Exp Med. 2015;8(5):8122-8. [PubMed: 26221379].

8. Etemadi-Aleagha A, Akhgari M, Iravani FS. Aluminum Phosphide Poisoning-Related Deaths in Tehran, Iran, 2006 to 2013. Medicine (Baltimore). 2015;94(38):1637. doi: 10.1097/MD.0000000000001637. [PubMed: 26402837].

9. Nazarzadeh M, Bidel Z, Ayubi E, Asadollahi K, Carson KV, Sayehmiri K. Determination of the social related factors of suicide in Iran: a sys- tematic review and meta-analysis. BMC Public Health. 2013;13:4. doi: 10.1186/1471-2458-13-4. [PubMed: 23289631].

10. Zarghami M, Khalilian A. Deliberate self-burning in Mazandaran, Iran. Burns. 2002;28(2):115-9. [PubMed: 11900933].

11. Suhrabi Z, Delpisheh A, Taghinejad H. Tragedy of women's selfimmolation in Iran and developing communities: a review. Int J Burns Trauma. 2012;2(2):93-104. [PubMed: 23071907].

12. Aliverdinia A, Pridemore WA. Women's fatalistic suicide in Iran: a partial test of Durkheim in an Islamic Republic. Violence Against Women. 2009;15(3):307-20. doi: 10.1177/1077801208330434. [PubMed: 19139492].

13. Pridmore S, Walter G. Culture and suicide set points. German J Psychiatr. 2013;16(4):143-51.

14. Routley V, Staines C, Brennan C, Haworth N, Ozanne-Smith J. Suicide and natural deaths in road traffic-review. Melbourne, Australia: Monash University Accident Research Centre; 2003.

15. Ohberg A, Penttila A, Lonnqvist J. Driver suicides. Br J Psychiatry. 1997;171:468-72. [PubMed: 9463608].

16. Milner A, De Leo D. Suicide by motor yehicle "accident" in Queensland. Traffic Inj Prev. 2012;13(4):342-7. doi. 10.1080/15389588.2012.660253. [PubMed: 22817548].

17. Keskinen E, Pasanen A. Self-destruction in motor vehicle accidents: the proportion of suicides and negligent drivers in fatal motor vehicle accidents in 1974-75 and 1984-85 in Finland. J Traffic Med. 1990;18(4):179-85.

18. Moafian G, Aghabeigi MR, Heydari ST, Hoseinzadeh A, Lankarani KB, Sarikhani Y. An epidemiologic survey of road traffic accidents in Iran: analysis of driver-related factors. Chin J Traumatol. 2013;16(3):140-4. [PubMed: 23735547].

19. UNICEF . Road traffic injuries in Iran and their prevention. Islamic Republic of Iran UNICEF; 2015. [cited November 30, 2015]. Available from: http://www.unicef.org/iran/media_4783.html.

20. Khajehpour B. Iran's crisis on the roads. Iran Pulse 2013. [cited November 30, 2015]. Available from: http://www.al-monitor.com/pulse/ originals/2013/11/iran-traffic-deaths-crisis-roads.html. 